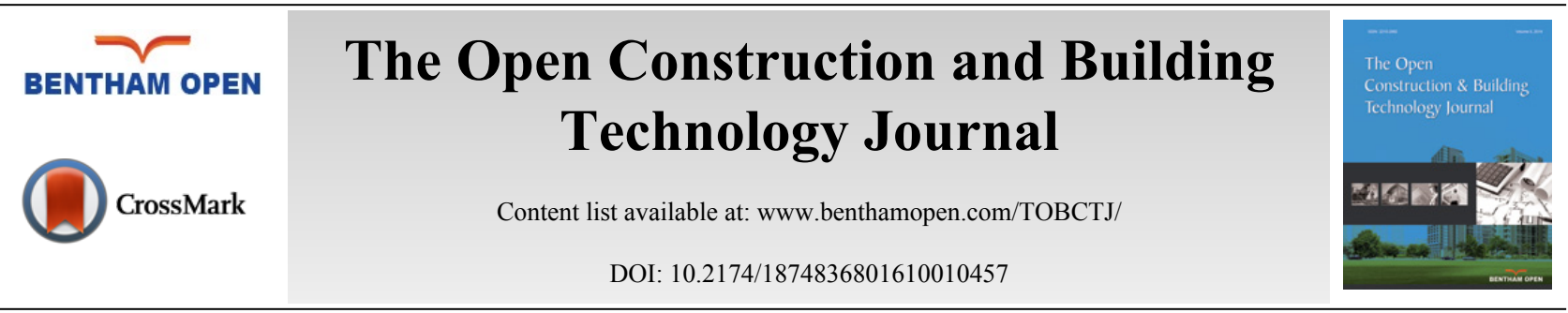

RESEARCH ARTICLE

\title{
Finite Element Analysis for Bearing Capacity of Prefabricated Arch Culverts
}

\author{
Bin $\mathrm{Zhu}^{1, *}$, Weifeng $\mathrm{Kou}^{2}$, Haibin $\mathrm{Li}^{1}$ and ${\mathrm{Ge} \mathrm{Li}^{1}}^{1}$ \\ ${ }^{I}$ School of Architecture and Civil Engineering, Xi'an University of Science and Technology, Yan Ta Street, Xi'an \\ 710054, China \\ ${ }^{2}$ Beijing Urban Construction Design \& Development Group Co.Limited, No.5, Fuchengmen Beidajie, Xicheng \\ District,100000, Beijing, China
}

\begin{abstract}
A new type of prefabricated arch culvert is consisted of precast arch pieces and cast-in-place concrete bases. The shape of precast arch pieces is confirmed by catenary theory. In the case of simulating placement in layers of embankment, internal forces of arch piece structure are statically analyzed by using finite element method. The results indicate that under the designed filling height, arch pieces mainly suffer from stress and only very little bending moment and shear force acted on them. The prefabricated arch culverts have reasonable structure stress and simple installation process, which can substantially save materials and shorten project duration of culverts with obvious economic benefits, and should be promoted and applied in mine highway engineering.
\end{abstract}

Keywords: Arch Culverts, Catenary Theory, Finite Elemen, Highway Engineering, Precast Arch Pieces, Static Analysis.

\section{INTRODUCTION}

The arch is a kind of common structural style. With reference to the earlier research on arches, there are various types of arches. Usually, arches are constructed in four basic shapes that frame and support doors, windows, porches, and other wall openings: flat arch, triangular arch, round arch and pointed arch. Its advantages are that it can transform the external force applied on it to stress with reasonable structure stress and that it can fully develop the compressive behavior of materials. The development of the arch was one of the most significant events in the history of structural design. Culvert is an opening through an embankment for the conveyance of water by mean of pipe or an enclosed channel. It is a transverse and totally enclosed drain under a road or railway. There are a lot of kinds of culvert and arch culvert is most common one. That is a round culvert reshaped to allow a lower profile while maintaining flow characteristics. It is good for installations with shallow cover. Materials used for arch culverts are RCC, corrugated metal or stone masonry. Hutchinson (2004) [1] research that arch culverts have had many applications in engineering, but most of them adopt the way of site construction; pipe culverts are traditional prefabricated culverts which are mostly applied, disadvantages of which are tedious installation process and unreasonable structure stress. He (2003) and Wang (2007) [2,3] discussed a new type of prefabricated arch culvert that is consisted of precast arch pieces and cast-in-place concrete bases, the structure diagram of which is shown in Fig. (1). The arch pieces and bases are connected in the way of hinge joint; and for the latter, separated bases or integral bases can be selected according to the bearing capacity of the foundation. The new type of prefabricated arch culverts absorbs advantages of arch structure and makes up disadvantages of fabricated pipe culverts with reasonable structure stress and substantially saving engineering materials, especially amount of reinforcement; meanwhile, the installation of arch pieces is simple, which can shorten project duration, realize smoothness of construction line in advance and lay a foundation for follow-up construction. Another

\footnotetext{
* Address correspondence to this author at the School of Architecture and Civil Engineering, Xi'an University of Science and Technology, Yan Ta Street, Xi'an 710054, China; E-mail: 31847844@qq.com
} 
benefit of this kind of arch culvert is simple method of construction. They can also be built with 2 crane operators and 3 laborers i.e., no highly skilled workers are necessary.

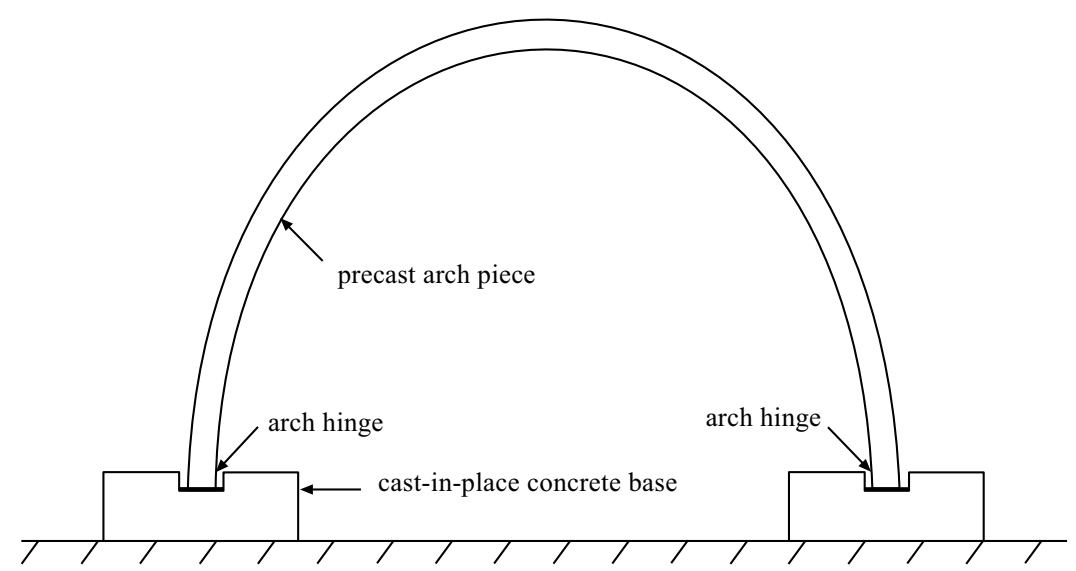

Fig. (1). Fabricated two-hinged arch culvert.

In this thesis, the shape of arch piece curve is confirmed by catenary theory. In the case of simulating placement in layers of embankment, internal forces of arch piece structure are statically analyzed by using finite element software of ANSYS. The results indicate that under the designed filling height, arch pieces mainly suffer from stress and only very little bending moment and shear force acted on them.

\section{CURVE SHAPE OF ARCH PIECES}

Under the action of vertical and horizontal earth pressure, the curve shape of arch pieces can be confirmed by catenary theory under earth pressure. The catenary theory is proposed by Matyas and Davis [4], principle of which is that: a rope bears the whole load only by tensile force and the curve shape of a rope after being subject to vertical and horizontal load effect is shown as Fig. (2a). If de-curved ropes are changed to upswept concrete arches and keep the force acted on arches identical to that acted on ropes as shown as Fig. (2b), new arch structures will only bear pressure action.

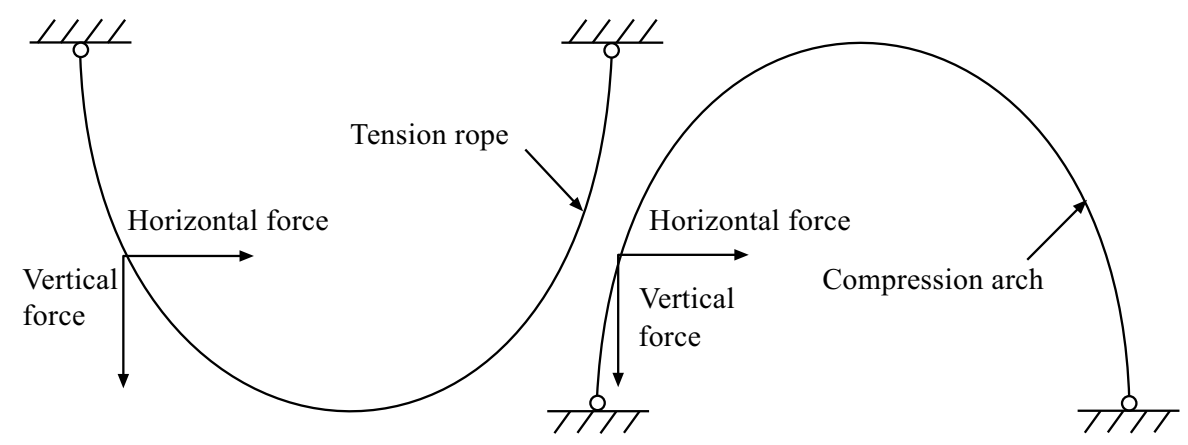

(a) Tension suspension curve $\quad$ (b) Compression arch curve

Fig. (2). Mechanical principle of catenary arch shape.

Under the action of vertical and horizontal earth pressure, the pure compression catenary arch curve obtained from catenary theory is a polynomial binary equation:

$$
\begin{aligned}
& \frac{\lambda}{6} y^{3}-\frac{\lambda(h+H)}{2} y^{2}-\frac{H}{12 L^{2}} x^{4}+\frac{H}{3 L} x^{3}-\frac{H+h}{2} x^{2} \\
& +L\left(h+\frac{H}{3}\right) x=0
\end{aligned}
$$


In the formula: $\lambda$-lateral earth pressure coefficient, $\lambda=\tan ^{2}(\pi / 4-\varphi / 2) ; \varphi$-internal friction angle of earth; please refer to Fig. (3) for other parameters. As the catenary arch curve is a polynomial binary equation, analytical solution can't be obtained directly, and the variable $y$ needs to be obtained indirectly through progressive increase of variable $x$. The arch curve is then fitted indirectly. The internal force on arch piece can be obtained through finite element analysis (FEA), whose result conforms to actual stress state of culvert.

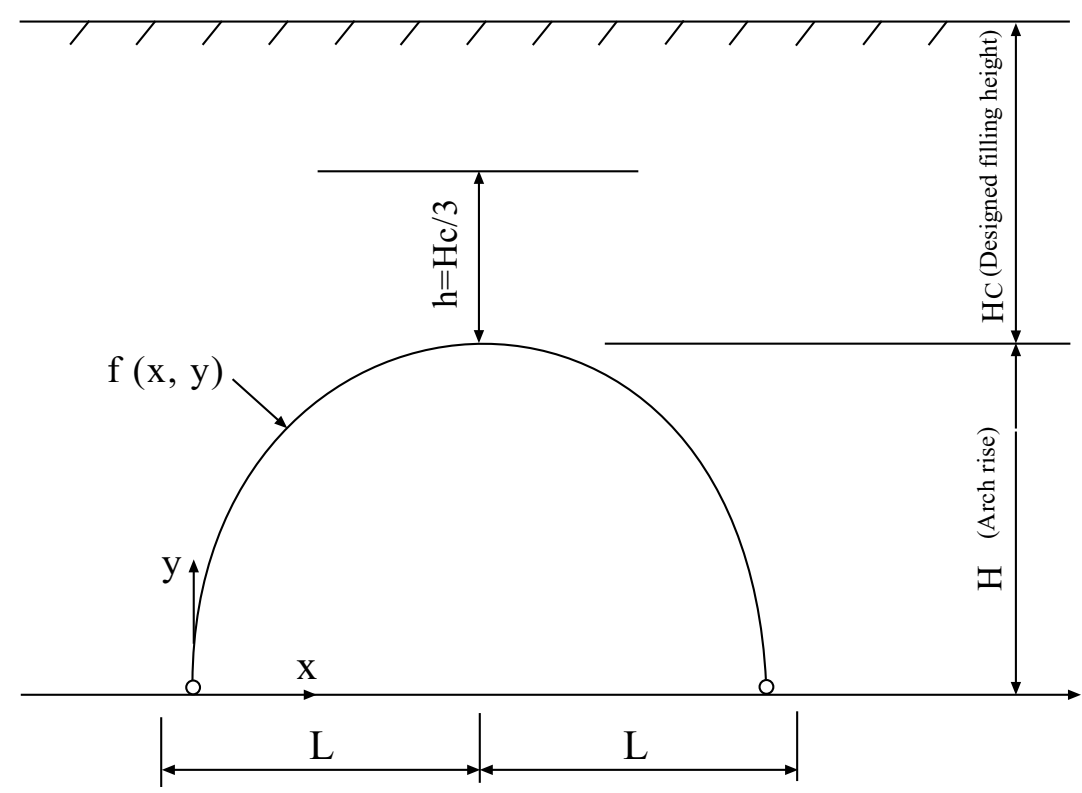

Fig. (3). Compression arch curve.

\section{INTERACTION BETWEEN CULVERT AND SOIL MASS}

The vertical earth pressure borne by culvert depends on relative settlement difference of inner soil column and outer soil column of culvert top plane [5,6]. As for positive buried culvert, with the load effect of upper part of backfill, because the rigidity of reinforced concrete culvert is far more than that of lateral soil of culvert, the settlement of outer soil column is more than that of inner soil column, thus the downward shear stress produced by outer soil column acts on inner soil column, making the actual earth pressure of culvert top be more than pressure of soil column, as shown in Fig. (4).

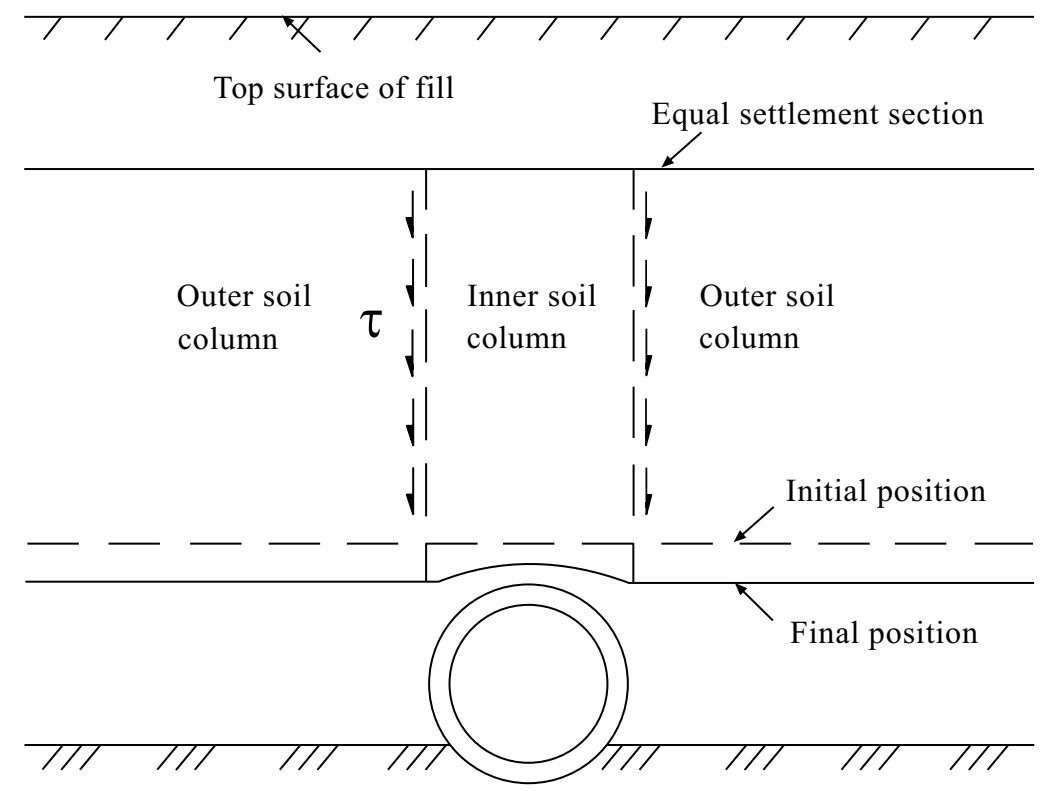

Fig. (4). Settlement difference of inner soil column and outer soil column of culvert top. 
The arch curve obtained from catenary theory on the premise that the culvert top bears pressure of soil column has underestimated the vertical earth pressure borne by the arch piece, so the arch piece will bear a certain amount of bending moment and shearing action; while the precast arch culvert belongs to positive buried rigid culvert, and the actual vertical earth pressure borne by arch piece will be larger than soil column pressure.

\section{FEA OF STRESS STATE OF CULVERT}

In the finite element model, the filling height of culvert top is $10 \mathrm{~m}$, and the effective span of arch culvert is $2.4 \mathrm{~m}$. The friction angle of backfill is $30^{\circ}$, introducing $\varphi$ value into relevant formula to obtain catenary arch curve, and the arch rise calculated is $1.95 \mathrm{~m}$, and its discharge area is close to that of pipe culvert with inner diameter of $2 \mathrm{~m}$.

\subsection{Selection of Model}

Simplify the finite element model of culvert into plane strain problem for consideration. Select plane quadrilateral 4node element for simulation of foundation and backfill; simulate the arch piece and separated base by adopting beam element; the arch piece and the base is connected through hinge joint. The overall width of the model is $24 \mathrm{~m}$, which is 10 times of width of culvert; the thickness of subsoil is $10 \mathrm{~m}$, meeting requirements for calculation accuracy. The lateral boundary only limits horizontal displacement; the bottom boundary node limits both the vertical and horizontal displacement (see Fig. 5)

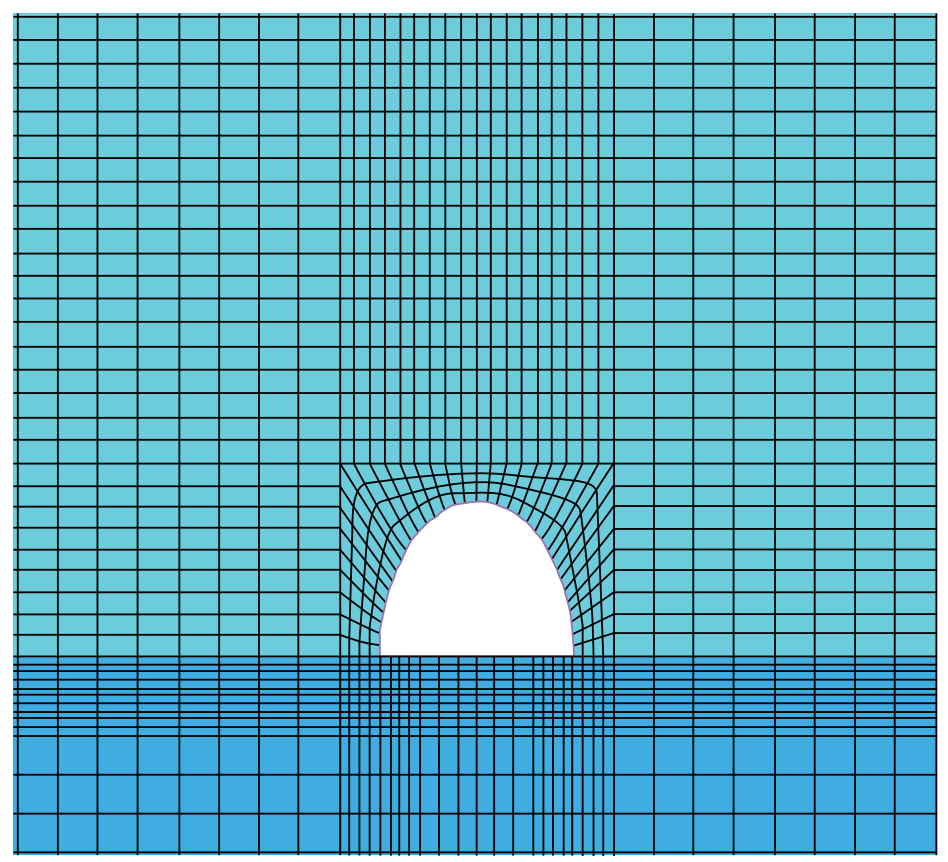

Fig. (5). Finite element model of culvert.

Assume that the foundation and backfill are ideal elastic-plastic models, and the yield criterion adopts MohrCoulomb criterion after modification; assume the concrete arch piece and foundation as elastic model, and the thickness of arch piece is $0.2 \mathrm{~m}$; the width of base is $1.0 \mathrm{~m}$, with thickness of $0.5 \mathrm{~m}$, and the parameter choices of various materials are listed in Table 1, in which E is Elastic modulus, $\mu$ is Poisson's ratio, $\mathrm{C}$ is Cohesion, pis Friction angle, $\gamma$ is unit weight.

Table 1. Calculation parameters of finite element model material.

\begin{tabular}{|c|c|c|c|}
\hline Parameter & Backfill & Foundation & Concrete culvert \\
\hline $\mathrm{E}(\mathrm{MPa})$ & 15 & 50 & 30000 \\
\hline$\mu$ & 0.33 & 0.30 & 0.17 \\
\hline $\mathrm{C}(\mathrm{kPa})$ & 17.0 & 40.0 & - \\
\hline$\varphi\left({ }^{\circ}\right)$ & 26.0 & 50.0 & 25.0 \\
\hline$\gamma\left(\mathrm{kN} / \mathrm{m}^{3}\right)$ & 19.0 & 22.0 & \\
\hline
\end{tabular}




\subsection{Simulation of Construction Process of Culvert}

The sequence of construction process of culvert: install culvert structure $\rightarrow$ backfill infrastructure pit $\rightarrow$ backfill overlying earth layer. Therefore, earth pressure borne by the culvert structure is exerted on the structure layer by layer, and the self-weight of each layer of filling only influences the earth layers filled in earlier stage [7]. Through simulation of construction loading engineering in layers, the loading function of construction of placement in layers can be reflected correctly, making the calculation result be more close to the actual situation of engineering [8].

If material is added to or removed from a system, certain elements in the model may become "existent" or "nonexistent". In such cases, element birth and death techniques could be used to deactivate or reactivate selected elements, respectively [9]. To achieve the "element death" effect, it does not mean that the "killed" elements are actually removed. Instead, they are deactivated by multiplying their stiffness (or conductivity, or other analogous quantity) by a severe reduction factor. This factor is usually set to $10^{-6}$. In like manner, when elements are "born", they are not actually added to the model; they are simply reactivated. All elements, including those to be born in later stages of the analysis, must be created while building the finite element model. New elements could not be created in solution process. To "add" an element, it should be first deactivated, then be reactivated at the proper load step.

This paper adopts birth-death element to simulate the construction process of placement in layers of embankment. Death element is realized by multiplication of element stiffness matrix and quality of backfill by a very small factor, that is: make its element load be close to 0 , and thus not to take effect on the load vector; when simulating filling in layers, re-activate the death element again, that is, each parameter in the model restores to its raw value, thus to realize the simulation of filling in layers. The thickness of each layer of simulation filling is $0.3 \mathrm{~m}$, and the model only considers static analysis of structure under the action of filling load, and does not consider the influence of load of construction machinery and vehicles.

Table 2. Max. internal force of arch piece (filling height of $10 \mathrm{~m}$ ).

\begin{tabular}{|c|c|c|c|c|}
\hline Max. internal force & Position & $\begin{array}{c}\text { Axial force N } \\
(\mathbf{k N})\end{array}$ & $\begin{array}{c}\text { Bending moment M } \\
(\mathbf{k N} \cdot \mathbf{m})\end{array}$ & $\begin{array}{c}\text { Shear force Q } \\
(\mathbf{k N})\end{array}$ \\
\hline Nmax & Arch hinge & 393.0 & 0.00 \\
\hline Mmax & Vault & 205.72 & 16.10 \\
\hline Qmax & 0.5 m higher than arch hinge & 360.65 & 205.71 \\
\hline
\end{tabular}

\subsection{Analysis of Numeric Simulation Result}

When the height of filling of culvert top is $10 \mathrm{~m}$, the internal forces of arch and base are shown in Fig. (6). It can be seen from the figure that, arch pieces mainly suffer from stress, with only a very small action of bending moment and shear force. The bending moment borne at the vault is the largest and the vault is designed control section, and maximum internal force and position of arch piece are shown in Table 2. Fig. (7) is the diagram of relationship between bending moment of vault and height of backfill; when the height of filled earth is less than $3 \mathrm{~m}$, the bending moment of vault is a negative value, which shows that when the filling is lower, the hogging moment of earth lateral pressure generated on the vault is greater than the sagging moment generated by the vertical earth pressure; when the height of filled earth is $3 \mathrm{~m}$, it is the critical height that hogging moment converts to sagging moment; when the height of filled earth is more than $3 \mathrm{~m}$, the bending moment of vault turns into a positive value, And it increases with the height of filling. Therefore, according to the catenary arch curve for the designed height of filled earth, it is applicable when the height of filled earth is lower than the designed height of filled earth, but is higher than the critical height.

In order to verify the superiority of the catenary arch stress, under the same conditions, use finite element to conduct analysis on structural internal force of a semicircular arch with $2.4 \mathrm{~m}$ span. Fig. (8) is the curve of relationship between internal force ratio of semicircular arch and catenary arch and the height of filling. Under the condition of same height of filling, the axial force of catenary arch is about 1.2 times of that of semicircular arch; shear force and bending moment are only about 0.2 times of that of semicircular arch, so the catenary arch can turn the earth pressure into the pressure of arch piece effectively, and stress performance of arch structure is better than that of semicircular arch culvert with the same span. 


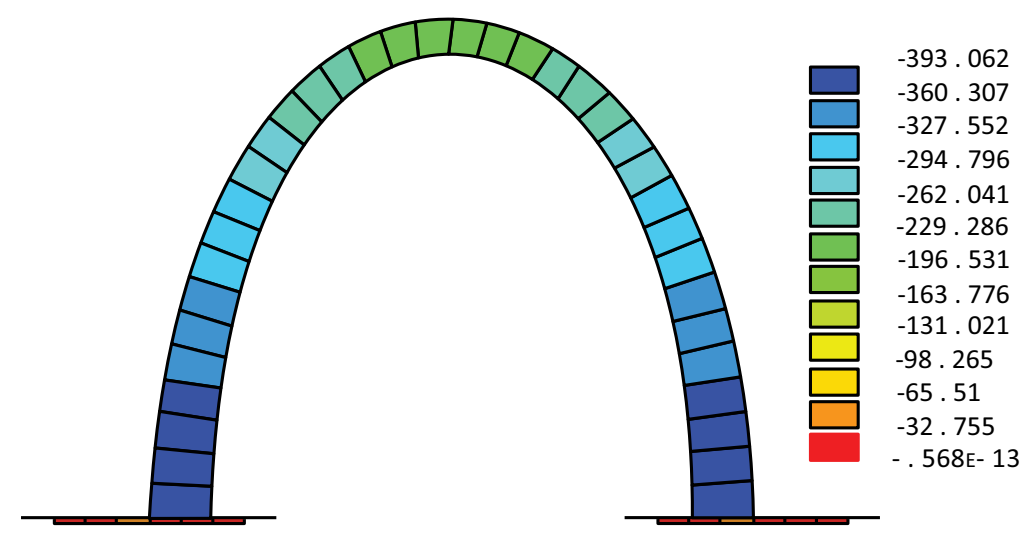

(a) Axial force of arch piece and base (Unit: $\mathrm{kN}$ )

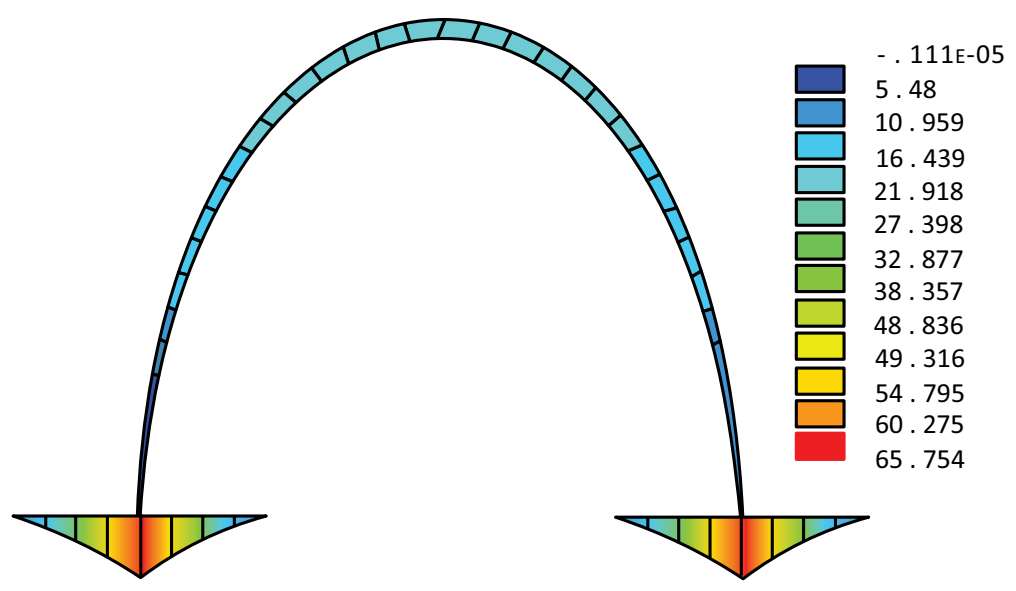

(b) Bending moment of arch piece and base (Unit: $\mathrm{kN} \cdot \mathrm{m}$ )

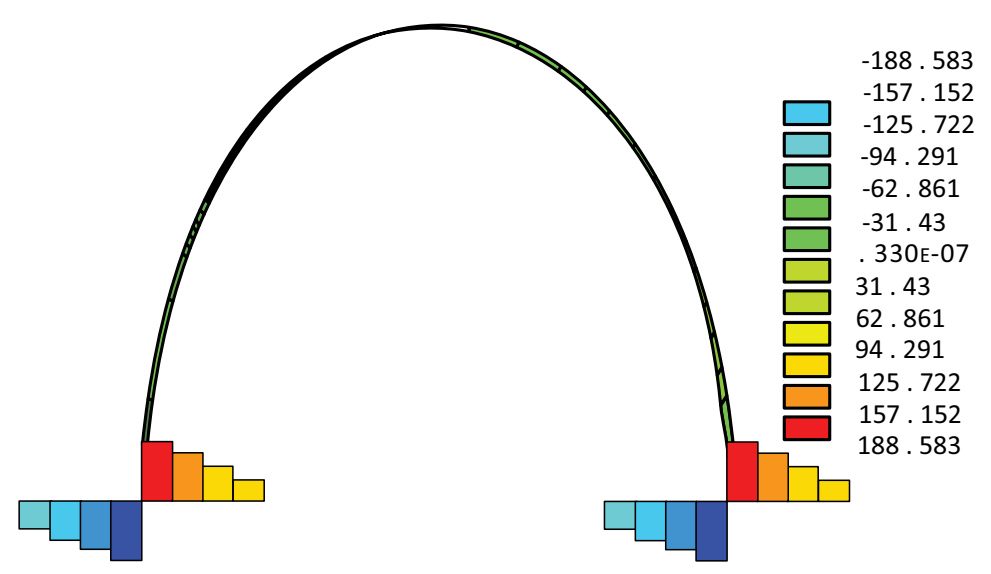

(c) Shear force of arch pieces and base(Unit: $\mathrm{kN})$

Fig. (6). Structural internal force of arch culvert under earth pressure. 


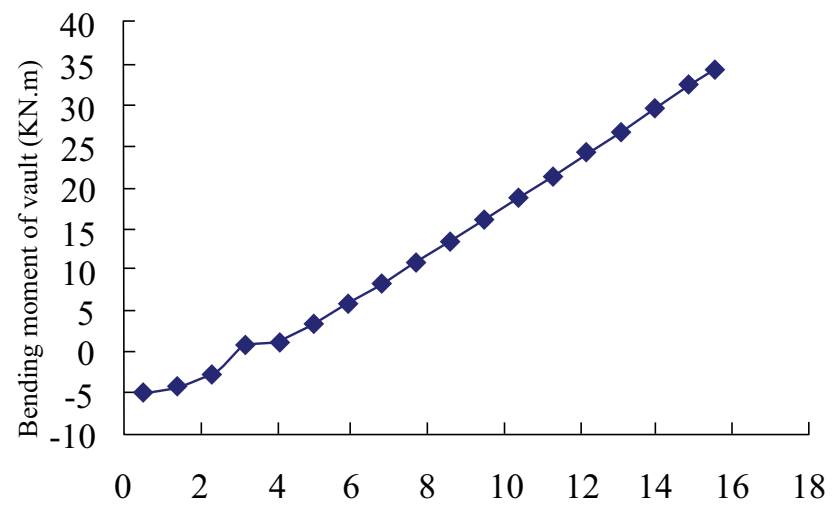

Fig. (7). Relationship between bending moment of vault and height of filling of vault.

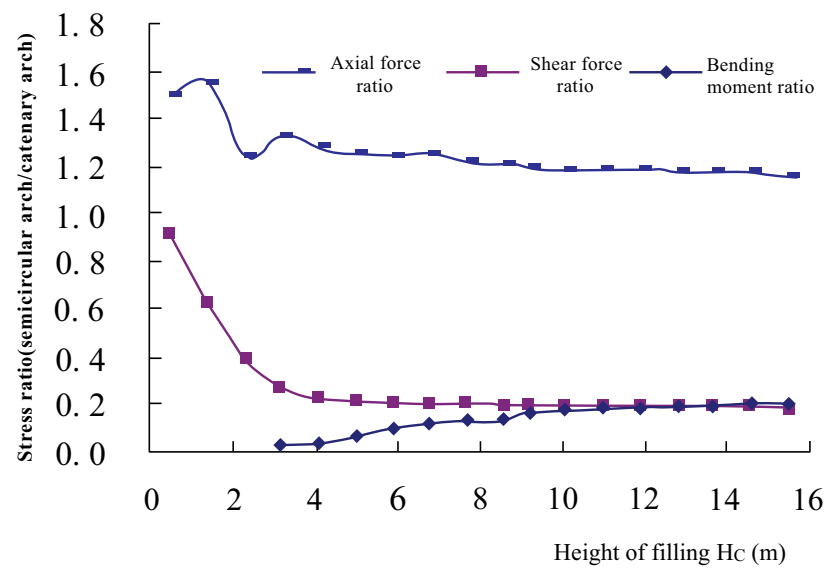

Fig. (8). Relationship between internal force ratio of semicircular arch and catenary arch and height of filling.

\section{DESIGN AND STRUCTURE}

\subsection{Structural Design}

The computing results of finite element, as characteristic value of a load (Table 2), are translated into design value of a load to be designed. The control section is designed at the vault, arch piece adopts $\mathrm{C} 30$ concrete, base adopts $\mathrm{C} 25$ concrete, load-bearing bar adopts HRB335 grade, and constructional steel bar adopts HRB235 grade. Calculated arch piece size and quantity of reinforcement are shown in Fig. (9), materials and installation weight of prefabricated arch culvert per linear meter are shown in Table $\mathbf{3}$.

Table 3. Consumption of precast arch culvert material per linear meter.

\begin{tabular}{|c|c|c|c|c|}
\hline \multirow{2}{*}{ Type } & \multicolumn{2}{|c|}{ Bar amount } & \multirow{2}{*}{ Concrete (m $\left.\mathbf{m}^{3}\right)$} & \multirow{2}{*}{ Total weight(T) } \\
\cline { 2 - 3 } & HRB235(kg) & HRB335(kg) & & \\
\hline Precast arch piece & 11.99 & 37.76 & 1.00 & 2.55 \\
\hline Cast-in-place concrete base & - & - & 1.05 & 2.63 \\
\hline
\end{tabular}

\subsection{Structural Measures}

According to the design size, cast-in-place concrete base should reserve installation groove with a depth of $10 \mathrm{~cm}$, installation groove width should be $5 \mathrm{~cm}$ greater than the thickness of arch piece, for ease of installation and alignment of arch piece. The installation groove elevation and construction positioning of plane position must be accurate to ensure the speed and quality of arch piece installation.

Due to combined action of culvert-soil, the vault is under a certain amount of bending internal force, and during the design process tensile bar of this area can be strengthened appropriately to avoid the vault crack subject to bending tensile stress, and save steel consumption of other cross sections of the arch piece. Each section of arch piece can be prefabricated into $1.5-2.0 \mathrm{~m}$ in length according to the production, transportation, lifting and other processes. After the 
arch piece is installed, arch hinge should be poured and filled with a high level concrete, and with waterproof processing, and other construction measures are the same with that of the installation of precast pipe culvert.

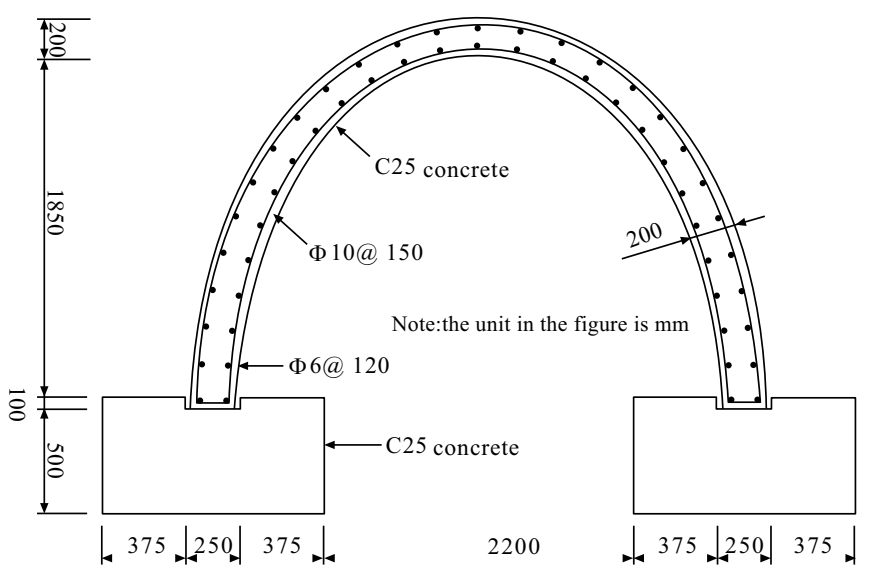

Fig. (9). Structure of fabricated arch culvert.

\section{CONCLUSION}

This paper presented an introductory study on behavior of a new type prefabricated arch culvert. The results show that:

1. Because of the effect of earth pressure, according to catenary theory, the catenary curve arch mainly suffers from pressure, with only small bending moment and shear force; therefore, it can give full play to the compressive properties of concrete.

2. The large-scale finite element software can consider culvert-soil interaction, the calculation results accord with actual stress state of culverts, so it can be directly used as the basis for arch culvert design.

3. The prefabricated arch culvert adopts the way of precast arch piece and cast-in-place concrete base, arch piece has reasonable structure stress, is easy to install, which can save a lot of materials, and shorten construction period of culvert, has obvious economic benefits, can be popularized and applied in highway engineering.

Based on the static analysis of prefabricated arch culvert, more work will be addressed to the lifting, construction and dynamic response of arch piece under earthquake shall ; and design theory of precast arch culvert should be improved combining the physical model and field test to lay a solid foundation to revise the relevant specifications.

\section{CONFLICT OF INTEREST}

The authors confirm that this article content has no conflict of interest.

\section{ACKNOWLEDGEMENTS}

This paper was supported by Natural Science Foundation of Shaanxi Province (2016JM4014)and the National Natural Science Foundation of China (41402265, 51508462).

\section{REFERENCES}

[1] P.E. David Hutchinson, Application and Design of Segmental Precast Arches., Geotechnical Engineering for Transportation Projects, 2004. [http://dx.doi.org/10.1061/40744(154)30]

[2] H. Yu, Technique for Precasting Arch Structure on the Top of Observation Corridor in Baishi Reservoir., Jilin Water Resources: Jilin, 2003, pp. 4-8.

[3] W. Yaoming, "Finite element analysis of culvert assembling", Construction and Engineering, vol. 21, no. 1, pp. 28-30, 2007.

[4] H. Hao, "Optimum design of concrete arch culvert. ", Transportation Science \& Technology, no. 1, pp. 13-15, 2008.

[5] E.L. Matyas, and J.B. Davis, "Prediction of vertical earth loads on rigid pipes", Journal of Geotechnical Engineering, no. 2, pp. 190-201, 1983.

[http://dx.doi.org/10.1061/(ASCE)0733-9410(1983)109:2(190)] 
[6] A. Gu, "Research of culvert and vertical earth pressure", Journal of Geotechnical Engineering, no. 1, pp. 3-15, 1981.

[7] L. Junwei, "Elastoplastic finite element simulation analysis of the whole processes during culvert construction", Chinese Journal of Rock Mechanics and Engineering, vol. 24, no. sl. 2, pp. 5634-5640, 2005.

[8] B. Yang, and J. Huang, "Temperature effects and calculation method of closure temperatures for concrete-filled steel tube arch rib of dumbbell-shape section", Open Civil Engineering Journal, vol. 5, pp. 179-189, 2011. [http://dx.doi.org/10.2174/1874149501105010179]

[9] S. Surendran, and H.B. Kaushik, "Masonry infill RC frames with openings: review of in-plane lateral load behaviour and modeling approaches", Open Construction \& Building Technology Journal, vol. 6, pp. 126-154, 2012. [http://dx.doi.org/10.2174/1874836801206010126]

(C) Zhu et al. ; Licensee Bentham Open.

This is an open access article licensed under the terms of the Creative Commons Attribution-Non-Commercial 4.0 International Public License (CC BY-NC 4.0) (https://creativecommons.org/licenses/by-nc/4.0/legalcode), which permits unrestricted, non-commercial use, distribution and reproduction in any medium, provided the work is properly cited. 